\title{
Pengaruh Kegiatan Lari ZigZag Melewati Balok Kayu Terhadap Kemampuan Motorik Kasar Anak di TK Aisyiyah Busthanul Athfal 01 Medan T.A 2020/2021
}

\author{
Sandra Azzahra Cempaka ${ }^{1}$, Jasper Simanjuntak ${ }^{2}$ \\ (1) Mahasiswa Program Studi PG PAUD FIP UNIMED \\ ${ }^{(2)}$ Dosen PG PAUD FIP UNIMED \\ Jl. Williem Iskandar Pasar V Medan Estate, Medan, Sumatera Utara, \\ 20371 Email : sandraazzahra99@gmail.com
}

\begin{abstract}
Abstrak : Penelitian Kuantitatif (Eksperimen) ini bertujuan untuk mengetahui pengaruh dari kegiatan berlari zigzag melewati balok kayu terhadap kemampuan motorik kasar anak. Sampel penelitian ini berjumlah 20 orang anak Teknik analisis data yang dilakukan pada penelitian ini adalah statistik deskriptif dan statistik nonparametrik melalui uji wilcoxon. Pengumpulan data menggunakan teknik observasi (checklist). Kegiatan lari zigzag ini dikatakan berhasil jika Ho diterima yang berarti terdapat perbedaan signifikan setelah melakukan kegiatan lari zigzag. Hasil Penelitian in membuktikan bahwa lari zigzag berpengaruh terhadap kemampuan motorik kasar anak kelompok B di TK ABA 01 Medan. Hal ini dibuktikan dengan jumlah skor anak bertambah 10,50 dilihat dari tabel analisis signed rank test. Hasil penelitian ini berpengaruh terhadap motorik kasar anak juga dapat dilihat dari pengujian hipotesis yaitu Ho diterima karena $W_{\text {hitung }} \geq W_{\text {tabel, }}$ yang dijabarkan sebagai berikut $\mathrm{W}_{\text {hitung }}=-46 \geq \mathrm{Wt}_{\text {tabel }}=52$.
\end{abstract}

Kata Kunci : Lari Zigzag, Kemampuan Motorik Kasar

\section{Pendahuluan}

Undang-undang Sistem Pendidikan Nasional tahun 2003, Pasal 1 ayat 14, menetapkan bahwa pendidikan anak usia dini adalah jenis arahan bagi anak sejak lahir hingga usia 6 tahun dengan memberikan stimulasi pendidikan untuk membangun pertumbuhan dan perkembangan mereka. Secara fisik dan mental, mempersiapkan anak untuk pendidikan lebih lanjut. Pendidikan anak usia dini (PAUD) memegang peranan yang sangat penting dalam perkembangan anak, karena transisi anak dari masa kanak- kanak ke pendidikan dasar merupakan masa emas yang tidak dapat terulang kembali dalam kehidupan manusia. Pendidikan Anak Usia Dini (PAUD) bertujuan untuk membimbing dan mengembangkan potensi setiap anak agar dapat memperoleh perkembangan yang terbaik sesuai dengan kemampuannya. Oleh karena itu, upaya untuk mengembangkan potensi anak secara penuh harus dimulai sejak usia sangat dini, agar tumbuh kembang anak dapat mencapai keadaan yang terbaik. 
Dalam proses perkembangan manusia, perkembangan gerak fisik memegang peranan yang sama pentingnya dengan perkembangan kognisi, perilaku sosial dan kepribadian, demikian pula untuk anak usia dini. Kemampuan fisik motoriknya sangat penting dikembangkan guna melakukan aktifitas yang mereka lakukan. Perkembangan motorik ada dua macam, yaitu motorik halus dan motorik kasar. Keterampilan motorik halus meliputi penggunaan otot-otot halus, seperti menulis, merajut, memotong, melipat, dll. Pada saat yang sama, keterampilan motorik kasar termasuk penggunaan otot-otot besar, seperti melompat, berlari, dan menendang.

Secara umum pembelajaran perkembangan fisik motorik di taman kanak-kanak lebih menitikberatkan pada perkembangan motorik halus, dan kurang memperhatikan motorik kasar. Perkembangan motorik kasar anak usia dini sama pentingnya dengan perkembangan lainnya. Perkembangan motorik kasar anak memerlukan bantuan tenaga pendidik di lembaga pendidikan anak usia dini, yaitu bagaimana mendapatkan pertolongan, cara pertolongan yang tepat, seberapa aman jenis olahraga untuk anak menurut usia, dan seberapa menyenangkan kegiatan fisik motorik tersebut untuk anak- anak.

Masalah tentang kemampuan motorik kasar yaitu pada komponen kekuatan dan keseimbangan pada anak. Contohnya yaitu anak kesulitan dalam berlari zigzag, anak kurang bisa mengendalikan keseimbangannya sehingga pada saat berlar zigzag anak hampir terjatuh karena badannya yang tidak seimbang ketika berlari zigzag. Melihat faktor penyebab masalah yang ada di TK ABA 01 Medan, maka perlu dirancang kegiatan alternatif yang dapat mengembangkan motorik kasar dan juga dengan keterlibatan guru secara optimal khususnya dalam melatih kelincahan dan kecepatan anak sekaligus mengatasi rasa jenuh saat melakukan kegiatan fisik motorik. Salah satu kegiatan alternatif yang dapat menyelesaikan permasalahan di TK ABA 01 Medan adalah dengan cara membuat kegiatan berlari zig-zag melewati balok kayu yang disusun berbentuk vertikal kemudian anak diminta berlari berbelok belok melewati balok kayu yang telah disusun.

Berdasarkan permasalahan yang ditemukan selama observasi dan telah dideskripsikan di atas, guru sebagai kolaborator dan peneliti berdiskusi untuk memecahkan masalah. Guru dan peneliti menggunakan balok kayu yang disusun secara vertikal untuk melakukan aktivitas lari zigzag untuk mengetahui cara meningkatkan kemampuan motorik kasar anak. Berdasarkan pertanyaan di atas, 
peneliti tertarik untuk melakukan penelitian yang berjudul "Pengaruh aktivitas lari zigzag kayu terhadap kemampuan motorik kasar anak".

\section{Metode Penelitian Jenis Penelitian}

Jenis penelitian yang dilakukan ialah penelitian kuantitatif (eksperimen). Yang mana metode ini bertujuan untuk mengetahui pengaruh dari kegiatan berlari zigzag melewati balok kayu terhadap perkembangan motorik kasar yang dilakukan pada anak. Berdasarkan Penjelasan Sugiyono (2014:h.107), menjelaskan bahwa metode penelitian eksperimen digunakan untuk mencari pengaruh perlakuan tertentu terhadap yang lain dalam kondisi yang terkendalikan.

Lokasi penelitian ini dilaksanakan di TK ABA 01 Medan T.A 2020/2021 yang berlokasi di Jalan Bugis No.01 Medan. Waktu penelitian ini dilaksanakan pada bulan April-Mei pada semester genap (2) tahun ajaran 2020/2021.

Populasi pada penelitian ini adalah semua anak kelas B TK ABA 01 Medan Tahun ajaran 2020/2021, yang terdiri dari 2 kelas. Total keseluruhan anak dikelas $\mathrm{B}$ adalah $\mathrm{N}=20$ orang. Adapun teknik pengambilan sampel dalam penelitian ini menggunakan purposive sampling. Menurut penjelasan Sugiyono(2010), menjelaskan bahwa Purposive Sampling ialah teknik untuk menentukan sampel penelitian dengan beberapa pertimbangan tertentu yang bertujuan agar data yang diperoleh nantinya representative. Maka, sampel pada penelitian ini adalah anak kelas B di TK ABA 01 Medan yang masing-masing anak di dalam kelas ini adalah kelas $\mathrm{B} 1=10$ orang dan kelas $\mathrm{B} 2=10$ orang.

Teknik pengumpulan data yang digunakan dalam penelitian ini adalah non tes yaitu observasi terstruktur. Untuk mempermudah pengamatan maka peneliti/*9 menggunakan instrumen penelitian berupa lembar observasi. Lembar pedoman observasi berisi sebuah daftar jenis kegiatan atau perilaku yang mungkin timbul dan akan diamati. Dalam proses observasi, observer hanya memberikan tanda cek list $(\checkmark)$ pada kolom sesuai skor yang didapat melalui pedoman observasi yang dibuat. Dari hasil observasi yang dilakukan maka akan diperoleh data tentang keterampilan motorik kasar anak.

Teknik analisis data yang dilakukan pada penelitian ini adalah statistik deskriptif dan statistik non parametik melalui uji Wilcoxon. Sebelum uji Wilcoxon 
dilakukan teknik analisis data melalui statistik deskriptif yaitu dengan langkahlangkah sebagai berikut :

a) Menghitung rata-rata

Mean merupakan teknik penjelasan kelompok yang didasarkan atas nilai ratarata data nilai yang dimaksud. Sudjana (2005: h.67)

Rumus : $:=\Sigma$

Keterangan :

$\mathrm{x} \quad=$ Rata-rata

$\sum \mathrm{xi} \quad=$ Jumlah nilai

skor anak $\mathrm{n} \quad=$ Jumlah

sampel

b) Menginterpretasikan hasil perhitungan rata-rata

Tabel interpretasi dapat dibuat dengan langkah-langkah sebagai berikut ini :

- Menentukan rentang : $\mathrm{R}=$ skor tertinggi - skor terendah

$$
\mathrm{Z}=4-1=3
$$

- Menghitung kelas interval (K) : ditetapkan ke dalam 4 kelas

- Menentukan interval :-nterate

$$
\text { Interval }=\frac{4-1}{4}=0,75
$$


Untuk menguji hipotesis apakah kebenarannya dapat diterima atau tidak, penelitian dilakukan dengan uji Wilcoxon sebagai berikut :

a. Menghitung nilai $\mathrm{W}_{\text {hitung }}$ dan $\mathrm{W}_{\text {tabel }}$, sebagai berikut: Membuat tabel penolong

- Menghitung selisih antara $X_{1}$ dan sampel $X_{2}$, dinotasikan dengan $D_{i}$

- Membuat semua nilai $D_{i}$ sama dengan nol, kemudian memberi peringkat dengan cara mengurutkan mulai dari yang terkecil sampai yang terbesar tanpa memperlihatkan tandanya (tanda bersifat absolut).

- Bila terjadi nilai yang sama diambil nilai rata-rata dari rangking-nya.

- Memisahkan antara tanda rangking positif dan negatif. Menjumlahkan tanda rangking positif dan negatif. Klasifikasi hasil penjumlahan rangking positif $\mathrm{T}_{\mathrm{r}(+)}$ dan negatif $\mathrm{T}_{\mathrm{r}(-)}$ dinyatakan sebagai $\mathrm{W}_{\text {hitung. }}$.

b. Menentukan nilai $\mathrm{W}_{\text {table }}$

Nilai $\mathrm{W}_{\text {tabel }}$ dapat dicari dengan menggunakan tabel Wilcoxon. Caranya, bila dua sisi $\mathrm{W}_{\text {tabel }}=\{(\alpha / 2)(\mathrm{n})\}$ dan satu sisi $\mathrm{W}_{\text {tabel }}=(\alpha)(\mathrm{n})$.

c. Kaidah pengujian

Terima Ho jika $\mathrm{W}_{\text {hitung }} \leq \mathrm{W}_{\text {tabel }(\alpha / 2) \text {. }}$

Tolak Ho jika $\mathrm{W}_{\text {hitung }}>\mathrm{W}_{\text {tabel }(\alpha / 2) \text {. }}$

d. Membandingkan antara $\mathrm{W}_{\text {hitung }}$ dan $\mathrm{W}_{\text {table }}$

e. Membuat kesimpulan

\section{Hasil dan Pembahasan}

Pelaksanaan penelitian eksperimen yang dilakukan oleh peneliti yaitu pertemuan pertama menentukan tema sesuai silabus dan kurikulum, menyusun rencana pembelajaran dalam bentuk RPPH dalam waktu 3 pertemuan, mempersiapkan alat pengumpul data, pedoman observasi, menetapkan kelas eksperimen dan kelas control, menetapkan rancangan media yang diperlukan sesuai dengan tema yang telah disusun sebelumnya. Selanjutnya peneliti melakukan observasi, kemudian menetapkan pembelajaran selanjutnya yaitu membuka pembelajaran, menetapkan pembelajaran dengan kegiatan berlari zigzag di kelas eksperimen dan menerapkan kegiatan melompat di kelas control dan melakukan observasi. Berikut adalah data kemampuan motorik kasar usia 5-6 tahun sebelum melakukan kegiatan berlari zigzag (pre-test) berdasarkan instrumen penelitian : 
Tabel 1. Sebelum Melakukan kegiatan Berlari Zigzag

\begin{tabular}{|c|c|c|c|c|c|c|c|}
\hline \multirow[t]{2}{*}{ Nama Anak } & \multicolumn{4}{|c|}{ Indikator } & \multirow{2}{*}{ Jumlah Skor } & \multirow{2}{*}{ Rata-rata nilai anak } & \multirow{2}{*}{ Ket } \\
\hline & 1 & 2 & 3 & 4 & & & \\
\hline Fairel & 2 & 3 & 2 & 1 & 8 & 2 & Cukup \\
\hline Nana & 1 & 2 & 2 & 2 & 7 & 1,75 & Kurang \\
\hline Novia & 3 & 3 & 2 & 2 & 10 & 2,5 & Cukup \\
\hline Nawal & 1 & 2 & 2 & 3 & 8 & 2 & Cukup \\
\hline Naura & 3 & 2 & 3 & 3 & 11 & 2,75 & Baik \\
\hline Fazri & 2 & 1 & 2 & 2 & 7 & 1,75 & Kurang \\
\hline Intan & 3 & 2 & 2 & 3 & 10 & 2,5 & Cukup \\
\hline Kenziro & 2 & 1 & 1 & 2 & 6 & 1,5 & Kurang \\
\hline Maira & 3 & 3 & 2 & 1 & 9 & 2,25 & Cukup \\
\hline Alya & 1 & 1 & 2 & 3 & 7 & 1,75 & Kurang \\
\hline Khayla & 2 & 3 & 1 & 1 & 7 & 1,75 & Kurang \\
\hline Ketrina & 2 & 2 & 1 & 3 & 8 & 2 & Cukup \\
\hline Hanif & 3 & 2 & 1 & 1 & 7 & 1,75 & Kurang \\
\hline Alisha & 2 & 2 & 2 & 3 & 9 & 2,25 & Cukup \\
\hline Fahri & 3 & 1 & 3 & 2 & 9 & 2,25 & Cukup \\
\hline Zhafran & 2 & 3 & 2 & 1 & 8 & 2 & Cukup \\
\hline Khayla & 2 & 1 & 2 & 3 & 8 & 2 & Cukup \\
\hline Aisyah & 3 & 3 & 3 & 1 & 10 & 2,5 & Cukup \\
\hline Fakhrie & 2 & 3 & 3 & 1 & 9 & 2,25 & Cukup \\
\hline Azka & 2 & 1 & 1 & 3 & 7 & 1,75 & Kurang \\
\hline
\end{tabular}

Keterangan :

$1 \leq 1,75=$ Kurang

$1,76 \leq 2,50=$ Cukup

$2,51 \leq 3,25=$ Baik 
$3,26 \leq 4,00=$ Baik Sekali

Berdasarkan Tabel diatas diketahui bahwa capaian kemampuan motorik kasar anak di TK ABA 01 Medan sebelum melakukan kegiatan lari zigzag masih tergolong dalam kriteria yang cukup rendah. Maka dari itu dilakukan kegiatan yaitu kegiatan berlari zigzag untuk meningkatkan kemampuan motorik kasar anak yang dijabarkan dengan tabel berikut :

Tabel 2. Setelah Melakukan Kegiatan Berlari ZigZag

\begin{tabular}{|c|c|c|c|c|c|c|c|}
\hline \multirow[t]{2}{*}{ Nama Anak } & \multicolumn{4}{|c|}{ Indikator } & \multirow[t]{2}{*}{ Jumlah Skor } & \multirow[t]{2}{*}{ Rata-rata nilai anak } & \multirow[t]{2}{*}{ Ket } \\
\hline & 1 & 2 & 3 & 4 & & & \\
\hline Fairel & 3 & 4 & 4 & 4 & 15 & 3,75 & Baik Sekali \\
\hline Nana & 4 & 3 & 3 & 3 & 13 & 3,25 & Baik \\
\hline Novia & 4 & 4 & 4 & 3 & 15 & 3,75 & Baik Sekali \\
\hline Nawal & 4 & 3 & 3 & 3 & 13 & 3,25 & Baik \\
\hline Naura & 3 & 4 & 3 & 4 & 14 & 3,5 & Baik Sekali \\
\hline Fazri & 4 & 3 & 3 & 3 & 13 & 3,25 & Baik \\
\hline Intan & 4 & 4 & 4 & 3 & 15 & 3,75 & Baik Sekali \\
\hline Kenziro & 3 & 3 & 3 & 4 & 13 & 3,25 & Baik \\
\hline Maira & 4 & 4 & 3 & 4 & 16 & 3,75 & Baik Sekali \\
\hline Alya & 3 & 3 & 3 & 4 & 13 & 3,25 & Baik \\
\hline Khayla & 4 & 3 & 3 & 3 & 13 & 3,25 & Baik \\
\hline Ketrina & 4 & 3 & 3 & 4 & 14 & 3,5 & Baik Sekali \\
\hline Hanif & 3 & 3 & 3 & 3 & 12 & 3 & Baik \\
\hline Alisha & 3 & 4 & 4 & 4 & 15 & 3,75 & Baik Sekali \\
\hline Fahri & 4 & 4 & 4 & 3 & 15 & 3,75 & Baik Sekali \\
\hline Zhafran & 3 & 3 & 3 & 4 & 13 & 3,25 & Baik \\
\hline Khayla & 4 & 4 & 3 & 3 & 14 & 3,5 & Baik Sekali \\
\hline Aisyah & 3 & 3 & 4 & 4 & 14 & 3,5 & Baik Sekali \\
\hline Fakhrie & 2 & 4 & 3 & 4 & 13 & 3,25 & Baik \\
\hline Azka & 2 & 4 & 4 & 3 & 13 & 3,25 & Baik \\
\hline
\end{tabular}

\section{Keterangan :}

$1 \leq 1,75=$ Kurang

$1,76 \leq 2,50=$ Cukup 
$2,51 \leq 3,25=$ Baik

$3,26 \leq 4,00=$ Baik Sekali

Dari Tabel diatas dapat disimpulkan bahwa terdapat perbedaan yang signifikan setelah anak melakukan kegiatan berlari zigzag. Terdapat peningkatan kemampuan motorik kasar anak setelah melakukan kegiatan berlari zigzag.

\section{Pengujian Hipotesis}

Hipotesis ini diajukan yaitu untuk menguji apakah kebenarannya dapat diterima atau tidak melalui tabel penolong sebagai berikut:

Tabel 3. Tabel Penolong Wilcoxon

\begin{tabular}{|c|c|c|c|c|c|c|c|}
\hline \multirow[t]{2}{*}{ Sumber Data } & \multicolumn{2}{|c|}{ Nilai } & \multicolumn{2}{|l|}{$\mathbf{D}_{1}$} & \multirow{2}{*}{$\begin{array}{l}\text { Rank } \\
\text { (r) }\end{array}$} & \multicolumn{2}{|c|}{ Tanda Rank } \\
\hline & $\mathbf{X}_{1}$ & $\mathbf{X}_{2}$ & $\mathbf{X}_{1-X_{2}}$ & & & $\mathbf{T}_{\mathbf{r}(+)}$ & $\mathbf{T}_{\mathbf{r}(-)}$ \\
\hline 1 & 2.45 & 3.15 & 0.70 & 0.70 & 6 & 6 & \\
\hline 2 & 2.35 & 3.25 & 0.90 & 0.90 & 7.5 & 7.5 & \\
\hline 3 & 3.20 & 3.10 & -0.10 & 0.10 & 1 & & -1 \\
\hline 4 & 2.45 & 3.45 & 1.00 & 1.00 & 12 & 12 & \\
\hline 5 & 2.25 & 3.25 & 1.00 & 1.00 & 12 & 12 & \\
\hline 6 & 2.40 & 3.35 & 0.95 & 0.95 & 10 & 10 & \\
\hline 7 & 2.35 & 3.40 & 1.05 & 1.05 & 14.5 & 14.5 & \\
\hline 8 & 2.20 & 3.40 & 1.20 & 1.20 & 17.5 & 17.5 & \\
\hline 9 & 2.55 & 2.40 & -0.15 & 0.15 & 2.5 & & -2.5 \\
\hline 10 & 2.20 & 3.30 & 1.10 & 1.10 & 16 & 16 & \\
\hline 11 & 2.00 & 3.35 & 1.35 & 1.35 & 19 & 19 & \\
\hline 12 & 2.15 & 3.20 & 1.05 & 1.05 & 14.5 & 14.5 & \\
\hline 13 & 2.30 & 3.50 & 1.20 & 1.20 & 17.5 & 17.5 & \\
\hline 14 & 2.75 & 2.25 & -0.50 & 0.50 & 5 & & -5 \\
\hline 15 & 3.20 & 2.20 & -1.00 & 1.00 & 12 & & -12 \\
\hline 16 & 2.40 & 3.80 & 1.40 & 1.40 & 20 & 20 & \\
\hline 17 & 2.55 & 3.35 & 0.80 & 0.80 & 7 & 7 & \\
\hline 18 & 2.60 & 2.40 & -0.20 & 0.20 & 4 & & -4 \\
\hline 19 & 2.25 & 3.15 & 0.90 & 0.90 & 8.5 & 8.5 & \\
\hline 20 & 2.35 & 2.20 & -0.15 & 0.15 & 2.5 & & -2.5 \\
\hline$\sum$ & & & & & & 183 & -27 \\
\hline
\end{tabular}


Klasifikasi hasil penjumlahan ranking positif $\mathrm{T}_{\mathrm{r}(+)}$ dan negatif $\mathrm{T}_{\mathrm{r}(-)}$ yang akan dinyatakan sebagai $\mathrm{W}_{\text {hitung. }} \mathrm{W}_{\text {hitung }}=156$

\section{Menentukan nilai $\mathbf{W}_{\text {tabel }}$}

Nilai $\mathrm{W}_{\text {tabel }}$ dapat dicari dengan menggunakan tabel Wilcoxon. Caranya, bila dua sisi $\mathrm{W}_{\text {tabel }}=\{(\alpha / 2)(\mathrm{n})\}$ dan satu sisi $\mathrm{W}_{\text {tabel }}=(\alpha)(\mathrm{n}) \mathrm{W}_{\text {hitung. }}$.

Tabel Wilcoxon dapat dijabarkan sebagai berikut :

\section{Tabel 4. Daftar Nilai Kritis Wilcoxon}

\begin{tabular}{|c|c|c|}
\hline \multirow[t]{2}{*}{ Ukuran Sampel } & \multicolumn{2}{|c|}{ Taraf Nyata } \\
\hline & $\mathbf{0 , 0 1}$ & 0,05 \\
\hline 6 & - & $\overline{\mathbf{0}}$ \\
\hline 7 & - & 2 \\
\hline 8 & 0 & 4 \\
\hline 9 & 2 & 6 \\
\hline 10 & 3 & 8 \\
\hline 11 & 5 & 11 \\
\hline 12 & 7 & 14 \\
\hline 13 & 10 & 17 \\
\hline 14 & 13 & 21 \\
\hline 15 & 16 & 25 \\
\hline 16 & 20 & 30 \\
\hline 17 & 23 & 35 \\
\hline 18 & 28 & 40 \\
\hline 19 & 32 & 46 \\
\hline 20 & 38 & 52 \\
\hline 21 & 43 & 59 \\
\hline 22 & 49 & 66 \\
\hline 23 & 55 & 73 \\
\hline 24 & 61 & 81 \\
\hline 25 & 68 & 89 \\
\hline
\end{tabular}

Jadi dari tabel wilcoxon diatas dapat disimpulkan $\alpha=0,05 \quad \mathrm{~W}_{\text {tabel }}=52$ karena jumlah sampel dalam penelitian ini sebanyak 20 anak yang dimana jika jumlah sampel 20 maka taraf nyata $0,05=52$. Pada hipotesis ini yaitu pengujian apakah 
Ho diterima atau ditolak dilihat dari $\mathrm{W}_{\text {hitung }}$ dan $\mathrm{W}_{\text {tabel }}$ yang telah ditentukan pada hipotesis sebelumnya yang dijabarkan sebagai berikut :

Terima Ho jika Whitung $\leq$ Wtabel $(\alpha / 2)$. Tolak Ho jika Whitung $>$ W tabel $(\alpha / 2)$.

Jadi dapat disimpulkan bahwa Ho diterima karena $\mathrm{W}_{\text {hitung }} \geq \mathrm{W}_{\text {tabel, }}$ yang mana dijabarkan sebagai berikut $\mathrm{W}_{\text {hitung }}=156 \geq \mathrm{W}_{\text {tabel }}=52$. Berdasarkan uraian dapat menjawab hipotesis penelitian yang berbunyi "Terdapat pengaruh lari zigzag melewati balok kayu terhadap kemampuan motorik kasar anak di TK Aisyiyah Busthanul Athfal 01 Medan".

\section{Kesimpulan}

Berdasarkan hasil analisis data dan pembahasan yang telah diuraikan dengan mengacu pada hipotesis yang dirumuskan dan tingkat kepercayaan 95\% $(\alpha=0,05)$, maka dapat disimpulkan beberapa hal sebagai berikut:

1. Kegiatan lari zigzag yang paling berpengaruh dalam meningkatkan kemampuan motorik kasar anak daripada kegiatan melompat. Berdasarkan hasil dari perhitungan Wilcoxom Rank Test, maka nilai $\mathrm{Z}$ yang didapatkan sebesar $3,985^{\text {b }}$ dengan $p$ value (Asymp. Sig 2-tailed) sebesar 0,000 dimana kurang dari batas krisis penelitian 0,05 sehingga keputusan hipotesis terdapat perbedaan bermakna pada kemampuan motorik kasar anak setelah diberikan kegiatan lari zigzag yang mana dapat disimpulkan sebagai "Terdapat pengaruh kemampuan motorik kasar anak terhadap kegiatan lari zigzag melewati balok kayu."

2. Ada pengaruh yang signifikan kegiatan lari zigzag terhadap kemampuan motorik kasar anak dengan hasil Ho diterima karena $\mathrm{W}_{\text {hitung }} \geq \mathrm{W}_{\text {tabel}}$, yang mana dijabarkan sebagai $\mathrm{W}_{\text {hitung }}=-46 \leq \mathrm{W}_{\text {tabel }}=52$.

Dengan penjelasan sebagai berikut :

Terima Ho jika Whitung $\leq$ Wtabel $(\alpha / 2)$. Tolak Ho jika Whitung $>$ Wtabel $(\alpha / 2)$.

\section{Daftar Pustaka}

Aida Farida (2016) : Urgensi Perkembangan Motori Kasar Pada Perkembangan Anak Usia Dini : Sumatera Utara : Universitas Islam Negeri Sumatera Utara.

Aip Syarifuddin. (1993). Pendidikan Jasmani dan Kesehatan. Jakarta: Proyek Pembinaan tenaga Kependidikan, Dirjen Pendidikan Tinggi, Depdikbud.

Danar Santi. (2009). Pendidikan Anak Usia Dini. Jakarta: Macanan Jaya 
Cemerlang. Dr. Hj. Khadijah, M.Ag (2008) . Pendidikan Prasekolah. Jakarta : Perdana Publishing.

Fitri Purwanti (2013) . Meningkatkan Kelincahan Anak Melalui Gerak Lokomotor Pada Anak Kelompok A2 TK ABA Gendingan Yogyakarta : Yogyakarta : Universitas Negeri Yogyakarta.

Husdarta dan Nurlan Kusmaedi. (2010). Pertumbuhan dan Kemampuan Peserta Didik (Olahraga dan Kesehatan). Bandung: Alfabeta.

Pravista Indah Sari (2015) . Upaya Meningkatkan Kemampuan Motorik Kasar Anak Melalui Lompat Tali Pada Kelompok A di TK ABA Ngabean I Tempel Sleman : Yogyakarta : Universitas Negeri Yogyakarta.

Prof. Dr. Sugiono (2009) . Metode Penelitian Pendidikan, Pendekatan Kuantitatif, Kualitatif, dan R\&D. Bandung : Alfabeta.

Rike Sulistiawati. (2017). Mengembangkan Kemampuan Motorik Kasar Anak Melalui Gerak Lokomotor Di Taman Kanak Kanak Widya Bhakti Tanjung Senang Bandar Lampung : Lampung : Universitas Negeri Lampung.

Rusli Lutan. (1997). Belajar Keterampilan Motorik, Pengantar Teori dan Metode. Jakarta: Depdikbud.

Samsudin (2008) . Pembelajaran Motorik Di Taman Kanak Kanak. Jakarta : Litera.

Siti Barokah (2018). Peningkatan Kemampuan Motorik Kasar Anak Melalui Permainan Lari Zigzag Pada Anak Kelompok B di Taman Kanak Kanak: Yogyakarta : Universitas Negeri Yogyakarta.

Susiani (2016) . Meningkatkan Kemampuan Motorik Kasar Melalui Permainan Lari Zigzag Dengan Metode Demonstrasi Pada Anak Kelompok B di TK Dharma Wanita Karangrejo I Kecamatan Ngasem Kabupaten Kediri : Kediri : Univeritas Nusantara PGRI Kediri.

Yudha M. Saputra. (2005). Perkembangan Gerak. Departemen Pendidikan Nasional Direktorat Direktur Jenderal Manajemen Pendidikan Dasar dan Direktorat Pembinaan Sekolah Luar Biasa. 